\title{
Omega-3 as an adjunctive to non surgical treatment of chronic periodontitis patients
}

\author{
Suzan Ali Salman B. D. S, M.Sc, Hadeel Mazin Akram B. D. S, M.Sc, \\ Omar Husham Ali B. D. S, M.Sc
}

\begin{abstract}
:
Background: Host modulatory therapy has been proposed as a treatment for periodontal diseases. Omega-3 polyunsaturated fatty acids (PUFAs), including docosahexaenoic acid (DHA)and eicosapentaenoic acid (EPA), were shown to have therapeutic anti-inflammatory and protective actions in inflammatory diseases including periodontitis.

Aim of study: To test the effect of Adjunctive treatment of chronic periodontitis with daily dietary supplementation with omega-3 fatty acid

Material \& Method: Fifty patients with chronic periodontitis were enrolled in this study, in a double blind clinical study. the control group was treated with scaling and root planning $(S R P)$ and a placebo, where as the study group was treated with SRP followed by dietary supplementation of Omega-3 ( $1000 \mathrm{mg}$ EPA+DHA) for three months . plaque and gingival index, bleeding on probing, probing depth were recorded at base line, after 1 and 3 months after treatment.

Results: the omega-3 group had highly significant lower scores for Plaque index( $P<0.001)$, gingival index(GI $P<0.001)$ and significant lower scores for the probing pocket at all examination than did the control group. At first visit mean PLI scores was 1.94 after three months it was 0.73. for the GI it was 1.98 at first visit, after three months it was 0.733.for PPD it was 4.79 was reduced to 3.05 after three months.

Conclusion: The results of this study suggest that dietary supplementation with omega-3 may provide a sustainable, low cost intervention to augment periodontal therapy.
\end{abstract}

Key word: omega-3, fish oil, periodontal disease.

\section{Introduction}

Periodontitis is a common, chronic inflammatory disease caused by the accumulation of bacterial matrix at the gingival line. It is characterized by gingival tissue separation from the tooth, which forms a periodontal pocket and can lead to bone and tooth loss. Traditional therapies for periodontitis focus on targeting the bacterial infection, which may be the initiating event responsible for the ensuing inflammation and tissue destruction. More recent therapeutic strategies have targeted the host response to the bacterial infection, which may play a more crucial role in the pathogenesis of periodontitis and its associated systemic effects. In animal models, induced periodontitis induces fatty plaque buildup in blood vessels ${ }^{(1)}$ which appears to be due to host inflammatory responses to the bacteria, rather than the bacteria ${ }^{(2)}$ Polyunsaturated fatty acids (PUFAs) are fatty acids with more than 1 carbon-carbon double bond, including omega 3 (n-3), omega 6 (n-6) and omega 9 (n-9) fatty acids. N-3s from marine sources, such as eicosapentaenoic acid (EPA) and docosahexaenoic acid (DHA), and vegetable sources, such as linolenic acid (LNA), which includes alpha-linolenic acid (ALA) and a related n6 fatty acid, gamma-linolenic acid (GLA), have all been shown to have anti-inflammatory properties ${ }^{.(3-5}$ ) Indeed systemic application of bioactive products derived from n-3 fatty acids (including DHA and EPA) confer dramatic protection against inflammation-induced tissue and bone loss associated with periodontitis in experimental models ${ }^{(6)}$

\section{Study Design}

\section{Material \& Method}

A randomized, three months , examiner blind, longitudinal clinical study.

Subject population: The participants were 50 systemically healthy male of an age ranged (30-60 years old) referred to the periodontal department in college of dentistry, Baghdad University who came to receive full mouth periodontal treatment. All patients were diagnosed to have chronic periodontitis. Each patient had to present with at least three periodontal sites in the two jaw quadrants' with a probing pocket depth(PPD) $>5 \mathrm{~mm}$ then following the baseline examination ,including assessment of plaque index, gingival index and probing pocket depth (PPD), careful instruction for oral hygiene was given. The patient were divided into two group each group contain 25 patients with chronic periodontitis matched with ages and scores, the first group was the study group treated by scaling and non surgical root planning with systemic intake of Omega- 3 of $1000 \mathrm{mg}$ 
once daily for three months and the second group was the control group was treated with scaling and non surgical root planning with placebo. Patients were advised of their role in this study and asked to provide informed consent. Extensive medical and dental histories were recorded for each patient. Patients with aggressive periodontitis or any systemic disorder that may affect the periodontal tissue (such as diabetes, pregnancy and immunological disorders), anemic patient, and smokers were excluded from the study. In addition to the baseline data the first recall visit was after one month then after three months to measure the clinical periodontal parameters .

Oral assessment: Periodontal Examination; Full mouth examinations (excluding third molars) were conducted for all patients. Four sites were examined for each tooth (buccal, lingual, mesial and distal). Plaque index $(\mathrm{PI})^{(7)}$, Gingival Index $(\mathrm{GI}){ }^{(8)}$, Probing Pocket depths (PPD) was measured from the free gingival margin to the most apical penetration of the periodontal probe inserted in gingival crevis periodontal probe. Examination were performed for all subjects at (first visit ) then at one and third months to assess efficacy of the test product. Data analyses were conducted by the application of the SPSS (Version 15) .

\section{Result:}

Descriptive and statistics were based on fifty participants who were present for all three examinations (baseline, $1^{\text {st }}$ month , 3 months)The average age of the subjects was 35.2 years.

\section{Plaque index results: (PLI)}

PLI results are reported in table (1) mean of baseline PLI score was 1.94 for the study group and 1.97 for the control group. Mean score at 1 months was reduced to 0.91 for the study group while its 1.55 for the control group . After 3 months, the study group mean of PLI was reduced to 0.73 but it was 1.1 for the control group.

By two way analysis, highly significant difference were noted when the study group was compared among the three visits $(\mathrm{P}<0.001)$ also highly significant difference occur for the control group (table 2). T-test was applied to test a comparison between study and control group, (table 3) that showed non differences at baseline visit , significant differences at first and third months visits

\section{Gingival Index result: (GI)}

GI results are reported in table (4)mean baseline GI score was 1.98 for the study group and 2.02 for the control group. Mean score after first month was reduced to 1.01 for the study group while its 1.59 for the control group . After 3 months, the study group mean of GI. Was reduced to 0.73 but it was 1.38 for the control group .By two ways analysis, highly significant difference were noted when the study group was compared among the three visits $(\mathrm{P}<0.001)$. $\mathrm{t}$ - test was applied to test a comparison between study and control group, table (6) showed no significant difference at baseline visit, significant difference at first and third months visits.

\section{Probing pocket depth result: (PPD)}

PPD results are shown in table (7) mean first visit PPD was 4.79 for the study group and 5 for the control group. Mean score after first month was reduced to 3.48for the study group while its 4.24 for the control group . After 3 months the score of PPD was reduced to 3.05 for the study group while its 4.3 for the control group. highly significant difference were noted when the study group was compared among the three visits $(\mathrm{P}<0.001)$. $\mathrm{t}$ - test was applied to test a comparison between study and control group . table (6) showed no significant difference at baseline visit, significant difference at first and third months visits.

\section{Discussion:}

Our study based on three periodontal parameters to assess the results of the study first of which is a plaque index and there was a highly significant reduction in both groups from the base line until the last visit after three months this is due to good motivation and co operation of patients in order to have optimum oral health for the starting of non surgical scaling and root planning, omega 3 was found to have strong antibacterial activity against a range of oral pathogens including Prphyromonas gingivalis at relatively low dose of omega $3^{(9)}$, may help in controlling plaque formation on tooth surfaces as shown by t- test.In table(3), the second periodontal parameter GI there was highly significant difference between the two groups at first and third months using the $t$ test .Omega 3 have been found to have anti-inflammatory effects through the production of nuclear transcription factors, enzymes and cytokines in human cells ${ }^{\cdot(10)}$ For example, Marion-Letellier et al found that DHA, EPA increased levels of peroxisome proliferator-activated receptor-gamma (PPAR- $\gamma$ ) and reduced production of the pro-inflammatory cytokines interleukin- 8 and interleukin- 6 . The strongest antiinflammatory effects tended to coincide with longer, more desaturated n-3 and n- 6 carbon chains, effects that are consistent with our primary analysis.Furthermore, $n-3 s$ have been found in animal models of periodontitis to be substrates for neutrophil production of resolvins and protectins, which appear central to the resolution of 
inflammation ${ }^{(11,12)}$ Other animal studies have suggested $\mathrm{n}-3 \mathrm{~s}$ may have a protective effect on periodontitis by decreasing the host inflammatory responses to common asaccharolytic microbial pathogens, such as Porphyromonas gingivalis. This decreased inflammatory reaction may result in less tissue breakdown, rendering these microbes unable to sustain their protein-derived energy source ${ }^{(13)}$. Our results was in agreement with many studies (El-Sharkawy et al ${ }^{(14)}$, Naqvi etal ${ }^{(15)}$, Thomas $\mathrm{E}^{(16)}$. In summary, we found that $\mathrm{n}$-3 intake, particularly DHA and EPA, are inversely associated with periodontitis in the US population. To date, the treatment of periodontitis has primarily involved mechanical cleaning and local antibiotic application. Thus, a dietary therapy, if effective, might be a less expensive and safer method for the prevention and treatment of periodontitis. Given the evidence indicating a role for $n-3 s$ in other chronic inflammatory conditions, it is possible that treating periodontitis with $\mathrm{n}-3 \mathrm{~s}$ could have the added benefit of preventing other chronic diseases associated with inflammation, including ischemic cerebrovascular disease, as well. Both of these questions warrant further investigation in prospective cohort and randomized clinical trials. ${ }^{(17)}$

\section{References}

[1]. Jain A, Batista EL, Jr, Serhan C, Stahl GL, Van Dyke TE. Role for periodontitis in the progression of lipid deposition in an animal model. Infect Immun. 2003;71:6012-8.

[2]. Serhan CN, Jain A, Marleau S, et al. Reduced inflammation and tissue damage in transgenic rabbits overexpressing 15lipoxygenase and endogenous anti-inflammatory lipid mediators. J Immunol. 2003;171:6856-65.

[3]. Zhao G, Etherton TD, Martin KR, Gillies PJ, West SG, Kris-Etherton PM. Dietary alpha-linolenic acid inhibits proinflammatory cytokine production by peripheral blood mononuclear cells in hypercholesterolemic subjects. Am J Clin Nutr. 2007;85:385-91.]

[4]. Eberhard J, Heilmann F, Acil Y, Albers HK, Jepsen S. Local application of n-3 or n-6 polyunsaturated fatty acids in the treatment of human experimental gingivitis. J Clin Periodontol. 2002;29:364-9.

[5]. Campan P, Planchand PO, Duran D. Pilot study on $n-3$ polyunsaturated fatty acids in the treatment of human experimental gingivitis. J Clin Periodontol. 1997;24:907-13.

[6]. Hasturk H, Kantarci A, Ohira T, et al. RvE1 protects from local inflammation and osteoclast- mediated bone destruction in periodontitis. FASEB J. 2006;20:401-3.

[7]. Silness J, Loe H. Periodontal disease in pregnancy II, correlation between oral hygiene and periodontal condition. Acta Odontol Scand ,1964, 22: 121- 135 .

[8]. Loe H, Silness J. Periodontal disease in pregnancy I. Prevalence and severity. Acta Odontol Scand, 1963, 21: 533- 551

[9]. Maria Tabba, Malden Golubic,Michael F.Roizen \&Adam M.Barnstein. Docosahexaenoic Acid, Inflammation \&bacterial dysbiosis in relation to periodontal disease, inflammatory bowel disease and the metabolic syndrom. Nutrient 2013,5,3299-3310.

[10]. Marion-Letellier R, Butler M, Dechelotte P, Playford RJ, Ghosh S. Comparison of cytokine modulation by natural peroxisome proliferator-activated receptor gamma ligands with synthetic ligands in intestinal-like Caco-2 cells and human dendritic cells-potential for dietary modulation of peroxisome proliferator-activated receptor gamma in intestinal inflammation. Am J Clin Nutr. 2008;87:939-48

[11]. Serhan CN, Savill J. Resolution of inflammation: the beginning programs the end. Nat Immunol. 2005;6:1191-7.

[12]. Levy BD, Kohli P, Gotlinger K, et al. Protectin D1 is generated in asthma and dampens airway inflammation and hyperresponsiveness. J Immunol. 2007;178:496-502.

[13]. Hasturk H, Kantarci A, Goguet-Surmenian E, et al. Resolvin E1 regulates inflammation at the cellular and tissue level and restores tissue homeostasis in vivo. J Immunol. 2007;179:7021-9.

[14]. Al-Sharkawy H, Aboelsaad N., Eliwa M, Darweesh M, AlShahat M.,Kantarci A, Hasturk H, Adjunctive treatment of chronic periodontitis with daily dietary supplementation with omega -3 fatty acids and low dose aspirin.J Periodontal.2010;81(11):1635-43.

[15]. Naqvi AZ,Buettner C, Philips RS, Davis RB ,Mukamal K J. n-3 fatty acids and periodontitis in US adults.J Am Diet Assoc. 2010;110(11):1669-75.

[16]. ThomasE.,Van Dyke.The Management of inflammation in periodontal disease. J Periodontal 2008; 79:1601-1608

[17]. Bahekar AA, Singh S, Saha S, Molnar J, Arora R. The prevalence and incidence of coronary heart disease is significantly increased in periodontitis: a meta-analysis. Am Heart J. 2007;154:830-7.

Table 1: Mean, standard deviation and standard error of PL.I for both groups at the three visits

\begin{tabular}{|l|c|c|r|r|r|r|}
\hline & \multicolumn{3}{|c|}{ study group } & \multicolumn{3}{c|}{ Control group } \\
\cline { 2 - 8 } & 1st visit & 1st month & 3rd month & 1st visit & 1st month & 3rd month \\
\hline $\begin{array}{l}\text { Mean+ } \\
\text { SE }\end{array}$ & $1.9425+0.13$ & $0.91+0.116$ & $0.737+0.08$ & $1.975+0.126$ & $1.55+0.099$ & $1.1+0.096$ \\
\hline SD & 0.4505 & 0.4019 & 0.296 & 0.437 & 0.345 & 0.3357 \\
\hline
\end{tabular}

Table 2: Intra group comparison between PL.I at different visits of the study and control groups

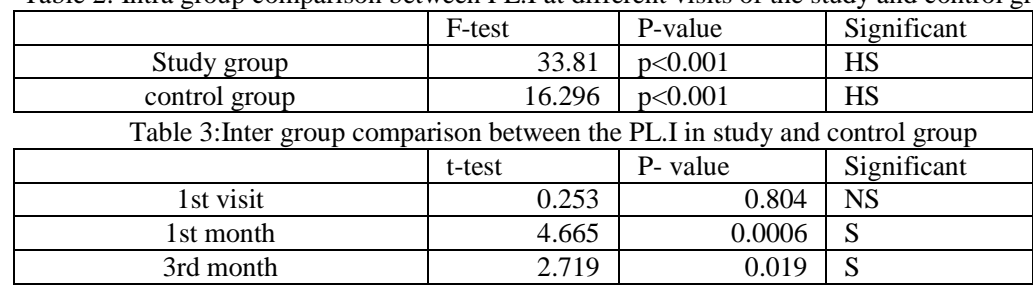


Table 4: Mean, standard deviation and standard error of GI for both groups at the three visits

\begin{tabular}{|l|r|r|r|r|r|r|}
\hline & \multicolumn{3}{|c|}{ study group } & \multicolumn{3}{c|}{ Control group } \\
\cline { 2 - 8 } & 1st visit & 1st month & 3rd month & 1st visit & 1st month & 3rd month \\
\hline Mean+ & & & & & & \\
SE & $1.982+0.1008$ & $1.015+0.0458$ & $0.733+0.054$ & $2.025+0.0729$ & $1.5916+0.120$ & $1.383+0.130$ \\
\hline SD & 0.349 & 0.1588 & 0.1875 & 0.252 & 0.418 & 0.4509 \\
\hline
\end{tabular}

Table 5: Intra group comparison between GI at different visits of the study and control groups

\begin{tabular}{|c|c|c|c|}
\hline & F-test & P-value & Significant \\
\hline Study group & 84.714 & $\mathrm{P}<0.001$ & HS \\
\hline control group & 8.716 & 0.000914 & HS \\
\hline
\end{tabular}

Table 6:Inter group comparison between the GI in study and control group

\begin{tabular}{|c|c|c|c|}
\hline & t-test & P-value & Significant \\
\hline & 0.355 & 0.7 & NS \\
\hline 1st visit & 4.68 & 0.00067 & HS \\
\hline 1st month & 4.913 & 0.000462 & HS \\
\hline
\end{tabular}

Table 7: Mean, standard deviation and standard error of PPD for both groups at the three visits

\begin{tabular}{|c|c|c|c|c|c|c|}
\hline & \multicolumn{3}{|c|}{ study group } & \multicolumn{3}{c|}{ Control group } \\
\cline { 2 - 7 } & 1st visit & 1st month & 3rd month & 1st visit & 1st month & $\begin{array}{c}\text { 3rd } \\
\text { month }\end{array}$ \\
\hline Mean+ SE & $4.793+0.1728$ & $3.4867+0.185$ & $3.058+0.1485$ & $5+0.2306$ & $4.2416+0.177$ & $4.3+0.157$ \\
\hline SD & 0.5987 & 0.642 & 0.5143 & 0.7988 & 0.6141 & 0.546 \\
\hline
\end{tabular}

Table 8: Intra group comparison between PPD at different visits of the study and control groups

\begin{tabular}{|c|c|c|c|}
\hline & F-test & P-value & Significant \\
\hline Study group & 28.388 & $\mathrm{P}<0.001$ & HS \\
\hline control group & 4.8805 & 0.0139 & $\mathrm{~S}$ \\
\hline
\end{tabular}

Table 9:Inter group comparison between the PPD in study and control group

\begin{tabular}{|c|c|c|c|}
\hline & t-test & P-value & Significant \\
\hline 1st visit & 0.7659 & 0.459 & NS \\
\hline 1st month & 2.978 & 0.0125 & S \\
\hline 3rd month & 5.7716 & 0.000124 & HS \\
\hline
\end{tabular}

